\title{
Influence of the Sodium Salt of 3a,7a-Dihydroxy-12-Oxo-5 $\beta$-Cholanate on Antimicrobial Activity of Ampicillin In Vitro
}

\author{
Ljiljana Suvajdžić', Slobodan Gigov², Aleksandar Rašković ${ }^{3}$ Srđan Stojanović², \\ Maja Bekut' ${ }^{1}$, Dubravka Milanov ${ }^{4}$, Ivana Čanak ${ }^{5}, S_{v e t l a n a}$ Goločorbin-Kon' ${ }^{1}$ Momir Mikov ${ }^{3}$
}

\begin{abstract}
Background: Multiple resistances to antibiotics are an emergent problem worldwide. Scientists intensively search for new substances with the antimicrobial potential or the mode to restore the activity of old-generation antibiotics. Ampicillin is the antibiotic with the expanded range of antimicrobial activity, but its use has decreased due to the poor absorption and highly developed resistance. In vivo studies showed that ampicillin has better absorption and bioavailability if combined with bile acid salts. The aim of this study was to examine antimicrobial effects of ampicillin alone and its combination with semisynthetic monoketocholic acid salt (MKH) in vitro.

Materials, Methods \& Results: In this study, commercial preparation of ampicillin and sodium salt of $3 \alpha, 7 \alpha$-dihydroxy-12oxo-5 $\beta$-cholanate were used. Their effects were evaluated on Escherichia coli (E. coli), Enterococcus faecalis (E. faecalis) and Enterococcus faecium (E. faecium), obtained from urine specimens of dogs with clinically manifested cystitis. The first two investigated strains were ampicillin-sensitive, while $E$. faecium was resistant to ampicillin. Modified macrodilution method according to Clinical and Laboratory Standards Institute Guidelines (M7-A8) was performed. Bacterial suspension equivalent to $0.5 \mathrm{McF}$ arland was prepared in saline, compared to the standard (Biomerieux) ad oculi. The density was checked spectrophotometrically at a wavelength of $625 \mathrm{~nm}$ and adjusted if necessary to the desired absorbance from 0.08 to 0.1. The resultant suspension was diluted 1:100 and inoculated in test tubes. Number of bacteria was counted on Petri plates using dilutions from $10^{-3}$ to $10^{-7}$ in order to obtain valid and countable plates. One hundred microliters of appropriate dilutions were aseptically plated in triplicate onto nutrient agar. Plates were incubated on $37^{\circ} \mathrm{C}$ for $72 \mathrm{~h}$, under aerobic conditions. The number of colony forming units (CFU) was determined by direct counting. As a valid for enumeration, we took plates with 30 to $300 \mathrm{CFU}$. Percentage of killed bacteria for ampicillin was from $69.33-95.19 \%$ for $E$. coli, 87.1296.92\% for E. faecalis and 7.20-33.30\% for E. faecium. Ampicillin applied in the combination with MKH killed 99.99\% to $100 \%$ of E. coli, $94.59 \%$ to $99.91 \%$ of E. faecalis and $31.73 \%$ to $64.76 \%$ of E. faecium. Mean percentage of killed bacteria for ampicillin was $81.93 \%$ for E. coli, $91.64 \%$ for E. faecalis, and $18.13 \%$ for E. faecium, while in combination with MKH percentage was $99.96 \%$ for E. coli, $98.23 \%$ for E. faecalis and $47.54 \%$ for E. faecium.

Discussion: Results are presented as pharmacological minimal inhibitory concentration (MIC) values. Ampicillin was applied at the concentration higher than the therapeutic one, which could explain high MIC values for $E$. coli and $E$. faecalis. The combination of ampicillin with MKH showed the best improvement of antimicrobial effect on E. faecium $(\Delta=$ $29.41 \%$ ), isolate that was resistant to ampicillin when applied alone. In all the investigated isolates, the combinations with MKH were more effective than ampicillin administered alone. It seems that MKH demonstrates a synergistic antimicrobial activity with ampicillin in vitro, which considerably decreases MIC values for all investigated isolates. These results implicate that MKH could restore the previous activity of ampicillin against some bacteria, which could be a significant benefit for clinical practice.
\end{abstract}

Keywords: antimicrobial effect, ampicillin, resistance, bile acid, in vitro. 


\section{INTRODUCTION}

Multiple resistances to antibiotics are fast growing problem in human and veterinary medicine [3$5,23,25]$. Scientists search both for new substances with an antimicrobial activity [8-10,21] and for new ways to restore the previous activity of older antibiotics.

Ampicillin is a cheap and safe drug with high therapeutic index. It had the expanded range of antimicrobial activity, but its use has decreased due to developing resistance. Unabsorbed part of the drug $(\approx 50 \%)$ causes reduction of gut microflora, which leads to diarrhea.

Bile acids promote transmembrane transport and increase absorption of drugs, which affects their pharmacokinetics $[13,20]$. Synthetic derivatives of bile acids enhance a drug transport across the blood-brain barrier [11,12,24]. Co-administration of ampicillin with bile acids protects normal intestinal flora [22]. Several in vivo studies showed better absorption and higher bioavailability of antibiotics if applied in the combination with bile acid salts $[6,16,22,27]$.

There is a question how this combination affects bacteria in vitro. Specific structure of bacterial cell wall (peptidoglycan) could be a reason for differences between the penetration through bacterial and mammal membranes. On the other hand, it is expected that there is analogy between them, and that bile acids decrease the surface tension of bacterial cell membranes $[1,7,18,26]$. This experiment was performed due to lack of in vitro studies on this subject available in literature.

The aim of this study was to evaluate differences between the antimicrobial effects of ampicillin alone and its combination with the sodium salt of $3 \alpha, 7 \alpha$-dihydroxy-12-oxo-5 $\beta$-cholanate $(\mathrm{MKH})$ in vitro.

\section{MATERIALS AND METHODS}

Investigated substances

Ampicillin ${ }^{1}$ commercial preparation for oral application in the form of a capsule by ICN Galenika, Serbia.

Cholic acid ${ }^{2}$ (98\%) was used for the synthesis and purification of the sodium salt of $3 \alpha, 7 \alpha$-dihydroxy12-oxo-5 $\beta$-cholanate $(\mathrm{MKH})^{3}$ according to the procedure by Miljković et al. [15].

\section{Investigated micoorganisms}

The investigated species included Escherichia coli (E. coli), Enterococcus faecalis (E. faecalis) and Enterococcus faecium (E. faecium). The first two strains were sensitive to ampicillin, while E. faecium was ampicillin-resistant. Isolates were obtained from the urine of golden retrievers with clinically manifested cystitis.

Design of experiment

An antimicrobial activity was investigated by a modified macrodilution method according to Clinical and Laboratory Standards Institute (CLSI) Methods for Dilution Antimicrobial Susceptibility Tests for Bacteria That Grow Aerobically [2].

Preparation of the bacterial suspensions (McFarland 0.5)

A bacterial suspension equivalent to 0.5 McFarland was prepared in saline, compared to the standard (Biomerieux) ${ }^{4}$ ad oculi. The density was checked spectrophotometrically at a wavelength of 625 $\mathrm{nm}$ and adjusted if necessary to the desired absorbance from 0.08 to 0.1 (Agilent 8453 UV-Visible Spectrophotometer $)^{5}$. The resultant suspension was diluted 1:100 and inoculated in test tubes. In this way, the inoculum density ranging from 1 to $5 \times 10^{5}$ organisms $/ \mathrm{mL}$ of the suspension was provided.

Evaluation of the number of formed colonies (colony forming units $=\mathrm{CFU}$ ) from such a suspension was done by counting colonies on the agar surface at dilutions from $10^{-3}$ to $10^{-7}$. One hundred microliters of appropriate dilutions were aseptically plated in triplicate onto the nutrient agar. Plates were incubated on $37^{\circ} \mathrm{C}$ for $72 \mathrm{~h}$, under aerobic conditions. The number of CFU was determined by direct counting. As a valid for enumeration, we took plates with 30 to $300 \mathrm{CFU}$ [2].

Ampicillin was applied at the concentration 10 $\mathrm{mg} / \mathrm{L}$ due to the analogy with commercial antibiogram disks for the routine identification of the antimicrobial susceptibility of bacteria. MKH was applied at the concentration $10 \mathrm{mmol} / \mathrm{L}$. Each assay was repeated four times $(n=4)$. In this study, a pharmacological minimal inhibitory concentration (MIC) and minimal bactericidal concentration (MBC), were determined. These values represent the percentages of killed bacteria in comparison to the number of bacteria that were brought into the experiment. MICn is the lowest concentration that kills $n$ percents of microorganisms inoculated in the experiment, for instance, $\mathrm{MIC}_{99}, \mathrm{MIC}_{90}$ and $\mathrm{MIC}_{80}$ are the lowest concentrations that kill $99 \%, 90 \%$ and $80 \%$ of microorganisms, respectively. MBC is the lowest concentration of the investigated substances that kills at least $99.9 \%$ of microorganisms inoculated in the experiment [21]. 


\section{Statistical analysis}

The level of significance between the groups was assessed with the Student's $t$-test for small independent samples using Excel software package (Microsoft Office 2007) ${ }^{6}$. All data are expressed as a mean \pm standard deviation (SD). A value of $P<0.05$ was considered to be statistically significant.

\section{RESULTS}

Ampicillin killed 69.33-95.19\% of E. coli when applied alone, and from $99.99 \%$ to $100 \%$ of the same strain when applied in the combination with MKH (Figure 1).

Similarly, an antibiotic applied alone eradicated $87.12-96.92 \%$ of E. faecalis while its combination

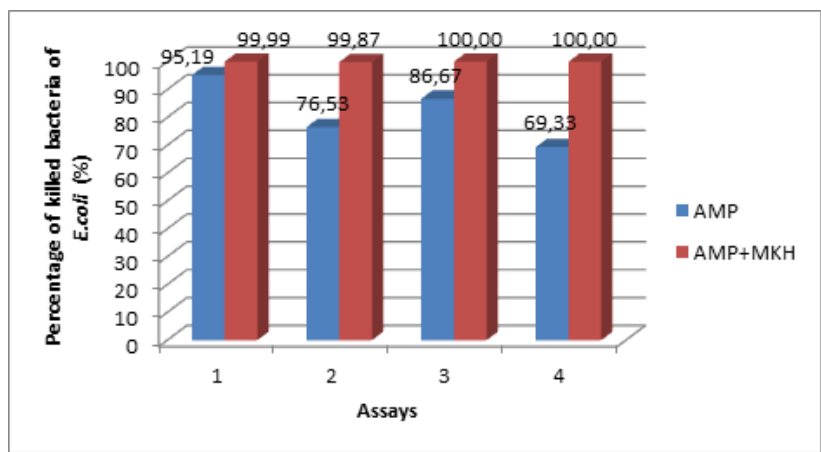

Figure 1. Comparison of antimicrobial effect of ampicillin and its combination with MKH on Escherichia coli. with MKH killed from $94.59 \%$ to $99.91 \%$ of the same strain (Figure 2).

The biggest difference in the percentage of killed bacteria was shown for E. faecium: from $7.20 \%$ to $33.30 \%$ when ampicillin was applied alone, and from $31.73 \%$ to $64.76 \%$ when applied in the combination with MKH (Figure 3).

Mean percentages of killed bacteria for ampicillin were $81.93 \%$ for E. coli $\left(\mathrm{MIC}_{81.93}\right), 91.64 \%$ for E. faecalis $\left(\mathrm{MIC}_{91.64}\right)$, and $18.13 \%$ for E. faecium $\left(\mathrm{MIC}_{18.13}\right)$. When ampicillin was administered with $\mathrm{MKH}$, mean percentages of killed bacteria were $99.96 \%$ for E. coli (MBC), $98.23 \%$ for E. faecalis (MIC98.23), 47.54\% for E. faecium $\left(\mathrm{MIC}_{47.54}\right)$ [Table 1].

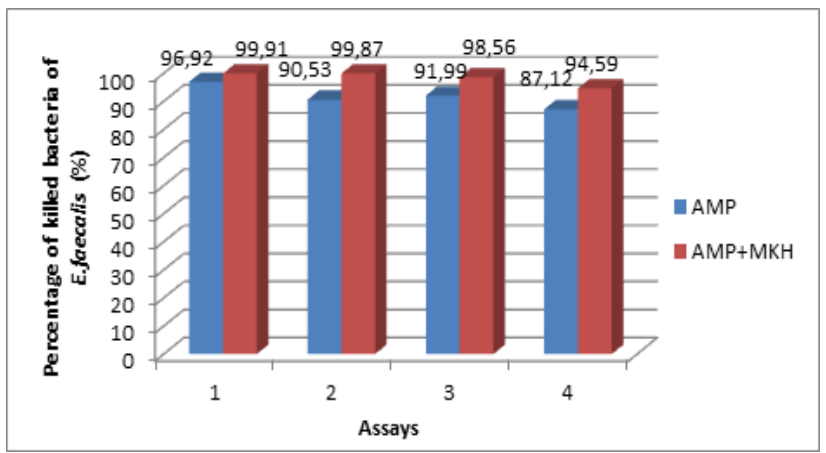

Figure 2. Comparison of antimicrobial effect of ampicillin and its combination with MKH on Enterococcus faecalis.

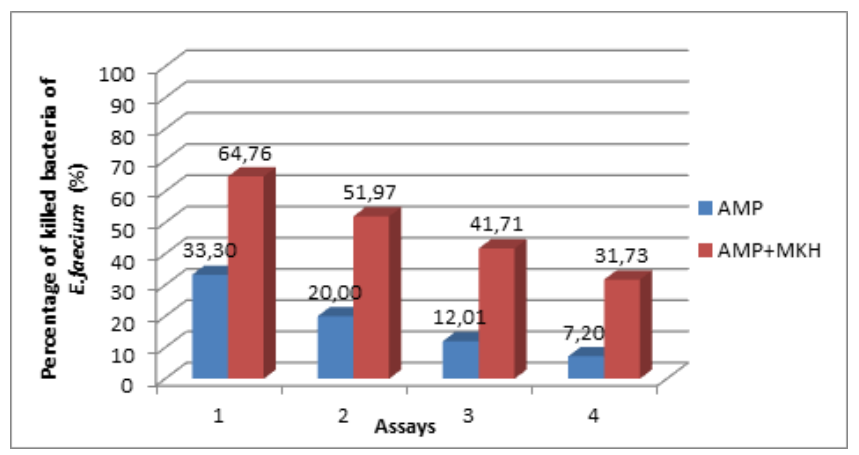

Figure 3. Comparison of antimicrobial effect of ampicillin and its combination with MKH on Enterococcus faecium.

Table 1. Percentage of killed bacteria for ampicillin and its combination with MKH.

\begin{tabular}{ccc}
\hline \multirow{2}{*}{ Investigated strain } & \multicolumn{2}{c}{ Percentage of killed bacteria(MIC) } \\
\cline { 2 - 3 } & Ampicillin $(\mathrm{n}=4)^{\ddagger}$ & Ampicillin + MKH $(\mathrm{n}=4)^{\ddagger}$ \\
\hline Escherichia coli & $81.93 \pm 9.82$ & $99.96 \pm 0.06^{*}$ \\
Enterococcus faecalis & $91.64 \pm 3.52$ & $98.23 \pm 2.17^{*}$ \\
Enterococcus faecium & $18.13 \pm 9.88$ & $47.54 \pm 12.25^{*}$ \\
\hline
\end{tabular}

†Four assays were conducted. *Significantly different from group treated with ampicillin alone $(P<0.05)$. All values are expressed as mean \pm standard deviation. 


\section{DISCUSSION}

The authors apply different interpretations of the term MIC (microbiological, epidemiological, and pharmacological) in the literature [21]. In this paper, pharmacological MIC was used. Ampicillin killed 69.33-95.19\% of E. coli, 87.12-96.92\% of E. faecalis and $7.20-33.30 \%$ of E. faecium organisms. When the same concentration of ampicillin was applied in the combination with $\mathrm{MKH}$, antimicrobial effects were significantly different: percentages of killed bacteria were in the following ranges: E. coli from $99.99 \%$ to $100 \%$, E. faecalis from $94.59 \%$ to $99.91 \%$ and $E$. faecium from $31.73 \%$ to $64.76 \%$ (Figures $1,2 \& 3$ ).

Ampicillin applied alone killed high percentage of bacteria, over $80 \%$ for E. coli and over $90 \%$ for E. faecalis (Table 1). Such high rate of killed bacteria can be explained by the fact that ampicillin was applied in the concentration of $10 \mathrm{mg} / \mathrm{L}$, which is more than the therapeutic one. After common oral dose of 500 $\mathrm{mg}$, the expected blood concentration of ampicillin is $3 \mathrm{mg} / \mathrm{L}$, while the concentration after intravenous application is $7 \mathrm{mg} / \mathrm{L}$ [19]. Ampicillin applied alone had a much weaker antimicrobial effect on E. faecium (mean value for MIC was 18.13\%) in comparison to E. coli and E. faecalis, despite its high concentration. This was rather expected, since the investigated isolate of E. faecium was resistant to ampicillin. Combinations with MKH had better effects on all investigated isolates than ampicillin applied alone. MIC values for E. coli and E. faecalis were raised from $81.93 \%$ to $99.96 \%(\Delta=18.03 \%)$ and from $91.64 \%$ to $98.23 \%$ ( $\Delta=6.59 \%$ ), respectively. The most significant difference between antimicrobial effects of ampicillin and its combination with MKH was demonstrated in E. faecium - the efficiency increased from $18.13 \%$ to $47.54 \%(\Delta=29.41 \%)$. The combination of ampicillin with MKH averagely showed 3.11 times (from 1.94 to 4.41 times) better antimicrobial effect on E. faecium than ampicillin applied alone (Figure 3).

Such an increase of antibacterial effect is most likely the result of E. faecium's resistance to ampicillin. The co-administration of ampicillin with $\mathrm{MKH}$ significantly increased MIC values, which provides new opportunities for the treatment of causative agents resistant to ampicillin.

Previous in vivo studies evaluated the benefit of the concomitant use of ampicillin and MKH due to the better absorption and bioavailability $[14,17]$ and the better preservation of normal gut flora [22]. This investigation demonstrated that the combination of ampicillin with MKH improves an antimicrobial activity in vitro, for which we have not found the comparable data in the available literature.

\section{CONCLUSIONS}

In vitro combinations of ampicillin and $\mathrm{MKH}$ manifested significantly better antimicrobial effects on all the investigated isolates than ampicillin alone. Furthermore, the concomitant use of ampicillin and MKH could be useful both for reducing harmful effects of ampicillin on the intestinal flora and for increasing of an oral bioavailability of ampicillin. The co-administration of MKH with ampicillin showed the most significant improvement of the antimicrobial effect on ampicillin resistant E. faecium, which suggests that MKH could block mechanisms of bacterial resistance to ampicillin.

These results implicate that MKH could restore the previous activity of ampicillin to some resistant bacterial strains.

\section{MANUFACTURERS}

${ }^{1}$ Galenika. Zemun, Serbia.

${ }^{2}$ Sigma-Aldrich ChemieGmbh. Munich, Germany.

${ }^{3}$ Department of Pharmacy, Faculty of Medicine, University of Novi Sad. Novi Sad, Serbia.

${ }^{4}$ BioMérieux SA, Marcy l'Etoile, France.

${ }^{5}$ Agilent Technologies Inc. Santa Clara, CA, USA.

${ }^{6}$ Microsoft Corporation. Redmond, WA, USA.

Funding. This work was supported by the Ministry of Education and Science, Republic of Serbia, Grant Number III 46012 and III 41012. The authors are grateful to professor Mihalj Poša, Department of Pharmacy, Faculty of Medicine, University of Novi Sad, for the synthesis of the sodium salt of $3 \alpha, 7 \alpha-$ dihydroxy-12-oxo-5 $\beta$-cholanate.

Declaration of interest. The authors declare that they have no conflict of interests.

\section{REFERENCES}

1 Atanacković M., Posa M., Heinle H., Gojković-Bukarica L. \& Cvejić J. 2009. Solubilization of resveratrol in micellar solutions of different bile acids. Colloids and Surfaces B: Biointerfaces. 72(1): 148-154. 
2 CLSI. 2009. Methods for Dilution Antimicrobial Susceptibility Tests for Bacteria that Grow Aerobically. Approved Standard M7-A8. 8th edn. CLSI. Wayne, PA. USA. 29(2): 16-17.

3 Damborg P., Top J., Hendrickx A.P., Dawson S., Willems R.J. \& Guardabassi L. 2009. Dogs Are a Reservoir of Ampicillin-Resistant Enterococcus faecium Lineages Associated with Human Infections. Applied and Environmental Microbiology. 75(8): 2360-2365.

4 De Campos T., Pisseti C., Werlang G.O., Lopes G.V., Kich J.D. \& Cardoso M. 2015. Antimicrobial Resistance of Enterococcus Isolated from Pre-Chill Swine Carcasses. Acta Scientiae Veterinariae. 43: 1259.

5 De Souze Lopez E., Maciel W.C., Albuquerque A.H., Machado D.N., Bezerra W.G.A., Vasconcelos R.H., Lima B.P., Gonçalves G.A.M. \& Teixeira R.S.C. 2015. Prevalence and Antimicrobial Resistance Profile of Enterobacteria Isolated from Psittaciformes of Illegal Wildlife Trade. Acta Scientiae Veterinariae. 43: 1313.

6 Golocorbin-Kon S., Mikov M., Arafat M., Lepojevic Z., Mikov I., Sahman-Zaimovic M. \& Tomic Z. 2009. Cefotaxime pharmacokinetics after oral application in the form of 3alpha, 7alpha-dihydroxy- 12-keto- 5beta- cholanate microvesicles in rat. European Journal of Drug Metabolism and Pharmacokinetics. 34(1): 31-36.

7 Gómez-Zavaglia A., Kociubinski G., Pérez P., Disalvo E. \& De Antoni G. 2002. Effect of bile on the lipid composition and surface properties of bifidobacteria. Journal of Applied Microbiology. 93(5): 794-799.

8 Krstić T., Suvajdžić Lj., Stojanović S., Crvenković-Lozanov Z., Dejanović J., Čabarkapa I., Velhner M. \& Stefanović V. 2016. Antimicrobial Activity of Sour Cherry. Agro Food Industry Hi Tech. 27(1): 56-58.

9 Krstić T., Suvajdžić Lj., Stojanović S., Petrović T., Bekut M., Ilić N. \& Suvajdžić Z. 2015. Antimicrobial activity of blackberry juice from Serbia on animal pathogens. In: Proceedings of First International Symposium of Veterinary Medicine ISVM2015 (Vrdnik, Serbia). pp.462-467.

10 Krstić T., Suvajdžić Lj., Stojanović S., Velhner M., Milanov D., Bojić G. \& Ilić N. 2014. Different antimicrobial effects of raspberry depending on the method of active components isolation. Food and Feed Research. 41(2): 125-130.

11 Lalić-Popović M., Vasović V., Milijašević B., Goločorbin-Kon S., Al-Salami H. \& Mikov M. 2013. Deoxycholic Acid as a Modifier of the Permeation of Gliclazide through the Blood Brain Barrier of a Rat. Journal of Diabetes Research. (17 i): 598603. [doi: 10.1155/2013/598603].

12 Mikov M., Kevrešan S., Kuhajda K., Jakovljević V. \& Vasović V. 2004. $3 \alpha$, $7 \alpha$-dihydroxy-12-oxo-5 $\beta$-cholanate as blood-brain barrier permeator. Polish Journal of Pharmacology. 56(3): 367-371.

13 Mikov M., Kuhajda K. \& Kandrač J. 2003. Savremeni pravci farmakološke primene žučnih kiselina. Medicinski Pregled. 56(5-6): 237-242.

14 Mikov M., Raskovic A., Jakovljevic E., Dudvarski D. \& Fawcett P. 2005. Influence of the bile salt sodium $3 \alpha$, $7 \alpha$ dihydrooxy-12-oxo-5 $\beta$-cholanate on ampicilin pharmacokinetics in rats. Asian Journal of Drug Metabolism and Pharmacokinetics. 5(3): 197-200.

15 Miljkovic D., Kuhajda K. \& Hranisavljevic J. 1996. Selective C-12 oxidation of cholic acid. Journal of Chemical Research. 2(2): 106-107.

16 Mrestani Y., Bretschneider B., Härtl A. \& Neubert R.H. 2003. In vitro and in vivo studies of cefpirom using bile salts as absorption enhancers. Journal of Pharmacy and Pharmacology. 55(12): 1601-1606.

17 Murakami T., Sasaki Y., Yamayo R. \& Yata N. 1984. Effect of bile salts on the rectal absorption of sodium ampicillin in rats. Chemical and Pharmaceutical Bulletin. 32(5): 1948-1955.

18 Posa M. \& Kuhajda K. 2010. Hydrophobicity and haemolytic potential of oxo derivatives of cholic, deoxycholic and chenodeoxycholic acids. Steroids. 75(6): 424-431.

19 Sabo A., Tomić Z., Rašković A. \& Stanulović M. 2014. Antibakterijski lekovi (sa ostalim antiinfektivnim lekovima). 4th edn. Novi Sad: Alfagraf, p.59.

20 Stojančević M., Pavlović N., Goločorbin-Kon S. \& Mikov M. 2013. Application of bile acids in drug formulation and delivery. Frontiers in Life Science. 7(3-4): 112-122.

21 Suvajdzic L., Leovac V., Joksovic M., Bogdanovic G., Kojic V., Vujic N., Mrdja T. \& Kocic B. 2013. Antimicrobial Activity of Copper (II) Complex with 1,2-bis [(1,3-diphenylpyrazol-4-yl)methyl] Diaminoethane. Acta Scientiae Veterinariae. 41: 1123.

22 Suvajdzic L., Stojakovic N., Mikov M., Satara S.S., Skrbic R., Vidic B., Dankuc D. \& Suvajdzic Z. 2015. Influence of Bile Acids on Rat Gut Microflora Deterioration Induced by Oral Ampicillin Treatment. Acta Scientiae Veterinariae. 43: 1282. 
23 Todorović D., Velhner M., Milanov D., Vidanović D., Suvajdžić Lj. \& Krnjaić D. 2015. Characterization of tetracycline resistance of Salmonella enterica subspecies enterica serovar infantis isolated from poultry in the northern part of Serbia. Acta Veterinaria-Beograd. 65(4): 548-556.

24 Vasović V., Vukmirović S., Mikov M., Mikov I., Budakov Z., Stilinović N. \& Milijašević B. 2014. Influence of bile acid derivates on morphine analgesic effect in mice. Vojnosanitski Pregled. 71(8): 767-771.

25 Velhner M., Suvajdžić Lj., Petrović J. \& Šeperanda M. 2012. Antimicrobial resistance of Escherichia coli in wild animals. Arhiv veterinarske medicine. 5(2): 35-44.

26 Waar K., Van der Mei H.C., Harmsen J.M., Degener J.E. \& Busscher H.J. 2002. Adhesion to bile drain materials and physicochemical surface properties of Enterococcus faecalis strains grown in the presence of bile. Applied and Environmental Microbiology. 68(8): 3855-3858.

27 Yang L., Zhang H., Mikov M. \& Tucker I.G. 2009. Physicochemical and biological characterization of monoketoholic acid, a novel permeability enhancer. Molecular Pharmaceutics. 6(2): 448-456. 